\title{
Sick leave certification: a unique perspective on frequency and duration of episodes - a complete record of sickness certification in a defined population of employees in Malta
} Jean Karl Soler*

Address: Family physician, Attard, MALTA

Email: Jean Karl Soler* - jksoler@synapse.net.mt

* Corresponding author

This article is available from: http://www.biomedcentral.com/I47/-2296/4/2

(C) 2003 Soler; licensee BioMed Central Ltd. This is an Open Access article: verbatim copying and redistribution of this article are permitted in all media for any purpose, provided this notice is preserved along with the article's original URL.

\begin{abstract}
Background: In Malta, sickness certificates are needed from the first day of illness, and are issued by family physicians (FPs) either employed by the government primary health care system, selfemployed in private practice, or employed by an employer for this purpose alone. The latter system, when applied by the employer, is compulsory. In order to contribute to the debate on the role of the FP in this context, electronic data collected by a group of company-employed FPs was used to study the phenomenon of sickness certification. This database is a complete record of the selected employees' sick leave certification during the study period.

Methods: Data collected by company-employed FPs from a defined population was used: all employees of selected Maltese companies served by a group of FPs. The database included episodebased data from home visits over three years (0I/0I//997 - 3I//2//999), by 9 company-appointed FPs regarding 421 employees of five companies.

Results: 3015 episodes of sickness absenteeism, with an average duration of 2.9 days, were documented. Employees who did intensive manual work had relatively higher rates. Furthermore, a relatively higher incidence of work injury, sprains and strains, anxiety and depression and low back pain as found in manual workers, and in male workers. This trend was shown to be statistically significant.

Conclusions: The frequency of sick-leave certification in Malta is comparable to that in other European countries, but the average duration of certificates is much less than reported in other studies that generally did not include data on short-term illness and certification. This has important implications on future research in the field. A number of common disorders were found to be significantly more prevalent causes of sickness certification in manual workers, amongst them anxiety and depression.
\end{abstract}

\section{Background}

Sick leave certification is an important element of family physicians' (FPs') day-to-day work, contributing significantly to their workload, as is certainly the case in Malta
[1-7]. Certification of sick leave is a reflection of the burden of illness in the community, and of the influence of national, cultural and social characteristics. Notwithstanding the importance of sickness leave certification, 
which may exceed as a financial burden on society even the costs of drug prescribing [5,6], relatively little discussion of it is available in the literature. The FP's certification practice has been the subject of relatively little research as compared to studies focusing on absence from work because of sickness itself and on the extent to which the working environment contributes to health problems resulting in sickness certification.

In order to contribute to the debate on the role of the FP in this context, data was collected from Maltese FPs' sickness certification practice in a fixed population of employees, analysed in an episode-oriented * model. Employees in Malta may obtain a sickness certificate from their personal self-employed FP, from a Government-employed FP in a health centre, or from the company-employed FP if the company provides one. It was impossible, although desirable, to collect usable data from Government-employed FPs due to the lack of patient records, very poor continuity of care inherent in the system, and inconsistent record-keeping systems in the Government health centres. Data from private self-employed FPs was collected in a separate study (referred to in Table 4). The data collected by company-employed FPs, presented here, is of specific unique interest as it represents a complete longitudinal episode-based sickness certification record of a fixed employee population.

The fact that in Malta certification of sickness by a doctor is necessary from the first day of illness, is part of the heritage of the Islands' socialist political background. Agius Muscat et al observed that the amount of clerical work in Maltese general practice is significantly higher than in other countries [1]. Although not an affluent country, Malta ranks very high in the World Health Report 2000 [8]. This is a reflection of local equality in access to relatively high quality health care for a relatively low price.

Employees can work from the age of sixteen to the age of 61 . The employer pays the first three days of sick leave in full for all full-time employees and participates in payment, with the Social Security system, for the rest of the sick leave entitlement (varies from 15 to 30 days on full pay). Injury on duty qualifies an employee for sick leave on full pay for up to one year. A Maltese employer has the right to appoint an FP as a company doctor, and may choose to honour only certification by him or her. This system of company-employed FPs is commonly found, and it is obligatory for the employee to report sick to the company FP, who will in turn visit him on the first day of sickness.

The data collected was used to answer three specific research questions:
1. What are the observed patterns of morbidity in employees who report sick to the FP from the first day of illness?

2. Do these patterns differ, especially in diagnostic title and length of episodes, from previous studies where sickness certification was not studied from day one?

3. The higher incidences of certain diseases (injury on duty, sprains and strains, low back pain, and anxiety/depression) evidently associated with manual type of work in the dataset prompted the systematic investigation of this phenomenon.

\section{Methods}

The database contains data from home visits over three full years (1997-1999) to a defined, stable population of 421 employees of five selected Maltese companies, performed by a group of 9 company-appointed FPs.

All employees who reported sick were seen by an FP at home, and the data returned to the author for reporting. Each episode of certification got a free text label diagnostic title, but no classification system or diagnostic guidelines were applied. The last diagnosis was used in the analysis: (e.g. if the original "URTI" label was eventually changed to "bronchitis" by the FP over two or more encounters for the same sickness episode, the entire episode's diagnosis was taken to be 'bronchitis'). Data was collected and stored in a customised Microsoft Access database. Data entry was done by the author personally and re-validated against written records at the end of every month. During analysis and data tabulation, rates of sickness certification were standardised to events per 1000 employees per annum.

To analyse the statistical significance of trends in sickness certification by diagnosis and type of work, odds ratios were calculated (exposure taken as manual against desk type of work, disease taken as being ever certified in three years with the particular diagnosis) for all workers, for male and for female workers, and significance measured as a p-value by applying the chi-squared test (Fisher's exact test used when small numbers precluded use of chisquare).

\section{Results}

In the three-year period the 9 company-appointed FPs performed 3423 visits to the population of 421 employees, for 3015 episodes of sickness for which 8869 days sick were prescribed. Thus the average sickness certification was 7.02 days and 2.39 episodes per employee per annum (7,020 days and 2,390 episodes per 1000 employees per annum), and the average duration of an episode of sickness was 2.9 days. The number of episodes of a specified duration is displayed in Figure 1, and it can be seen that 
Number of episodes

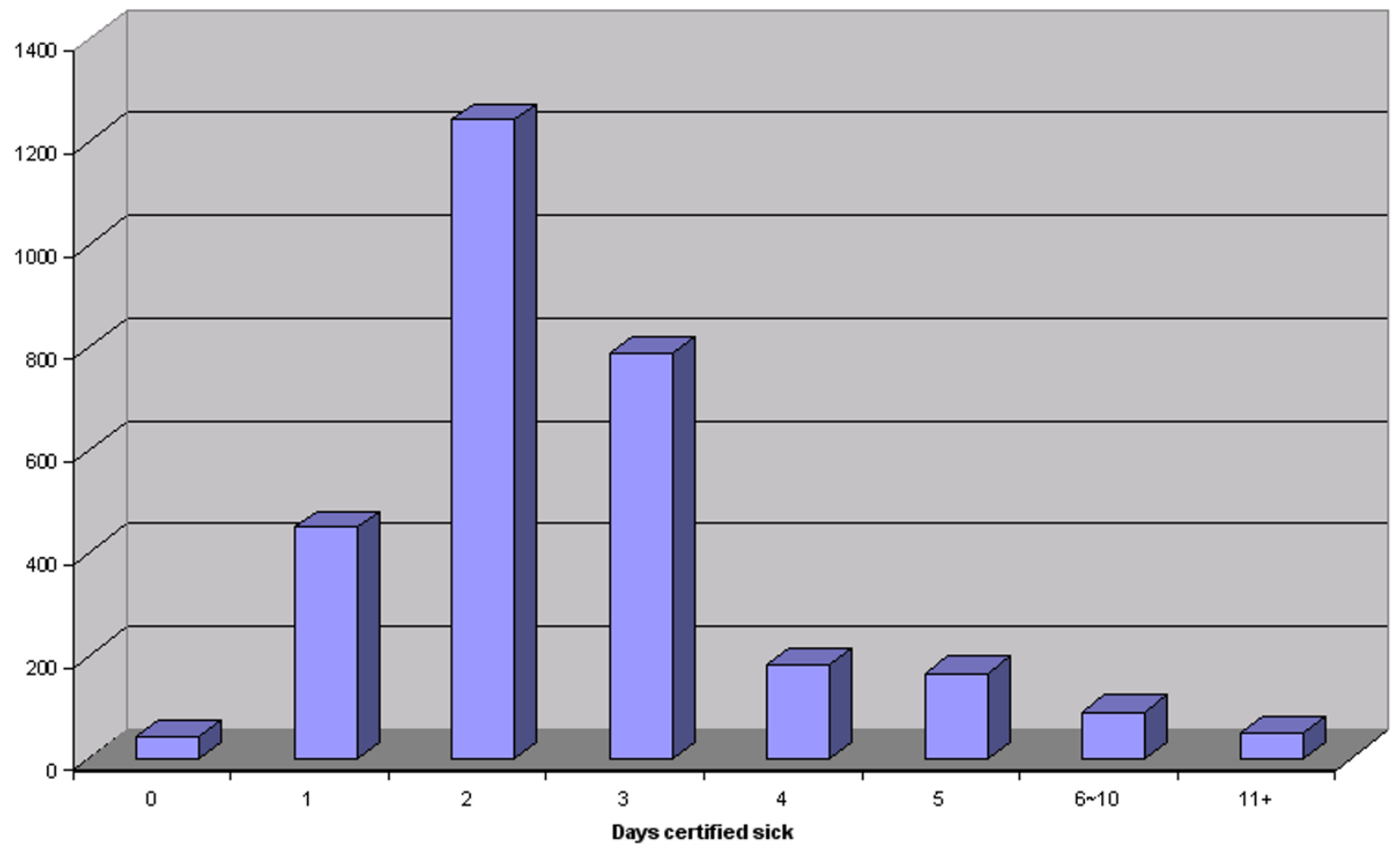

\section{Figure I}

Number of episodes of a specified duration in days. X-axis - number of days certified sick $Y$-axis - number of episodes of specified duration in days

the distribution is, as expected, skewed to the right. The data per company is presented in Table 1 : companies D and $\mathrm{E}$, where employees did intensive manual work, had relatively high overall sickness certification rates. Whereas the rates of episodes and days sick for injury on duty, strains and sprains and low back pain were also higher in companies $\mathrm{D}$ and $\mathrm{E}$, the figures for upper respiratory tract infections showed no such trend.

The three most common episodes were upper respiratory tract infections, sprains and strains, and gastro-enteritis (data not tabulated). It is notable that these Maltese workers relatively seldom received sickness absenteeism certification because of depression or anxiety.

In Table 2, the annual averages of episodes and days sick are presented by diagnostic title, broken down by category of employee (sex and type of work). The data collected allowed the opportunity to look in more detail at why sickness certification rates were higher in manual workers. It is clear that the sickness rates of injury on duty, sprains and strains, low back pain and psychological diagnoses are higher for male and manual workers, while the rates for URTI show no trend for sex or type of work. This trend was found to be significant for male and manual workers, as tabulated in Table 3 . It is probable that the trend was not found to be significant for female workers due to the small number in the study population.

\section{Discussion}

The global rates of sickness certification measured were almost identical to those subsequently reported from private companies in a concurrent but independent study on sick leave by the Malta Employer's Association, which therefore supports my results. The rates for employees in Government employment, which were not accessible for study as the Government does not routinely provide the services of a "company" FP, were reported to be much higher [9]. However, the companies and employees included in this study are not necessarily representative of 
Table I: Number (Episodes) and average duration (Days) of episodes by company (A to E); rates per 1000 employees per annum for selected diagnoses and for all diagnoses totalled.

\begin{tabular}{|c|c|c|c|c|c|c|}
\hline & Company & $A$ & $B$ & $C$ & $D$ & $E$ \\
\hline \multirow[t]{5}{*}{ Episodes } & Injury on duty & 10 & 29 & 17 & 167 & 200 \\
\hline & Sprains/Strains & 71 & 310 & 517 & 904 & 692 \\
\hline & Low back pain & 17 & 29 & 200 & 180 & 100 \\
\hline & Anxiety / Depression & 4 & 24 & 0 & 44 & 38 \\
\hline & Upper respiratory tract infection & 531 & 1,070 & 667 & 1,020 & 938 \\
\hline Total & All diagnoses & 1,140 & 2,680 & 2,400 & 3,740 & 3,580 \\
\hline \multirow[t]{5}{*}{ Days } & Injury on duty & 236 & 148 & 50 & 1,220 & 996 \\
\hline & Sprains/Strains & 170 & 652 & 1,300 & 2,220 & 1,760 \\
\hline & Low back pain & 44 & 91 & 667 & 952 & 304 \\
\hline & Anxiety / Depression & 8 & 267 & 0 & 132 & 446 \\
\hline & Upper respiratory tract infection & 1,290 & 2,660 & 1,870 & 2,760 & 2,380 \\
\hline Total & All diagnoses & 3,030 & 6,870 & 6,880 & 12,950 & 10,280 \\
\hline
\end{tabular}

Company A: a goods distributor/agency with 175 mostly young employees, $56 \%$ male, $80 \%$ with desk jobs; Company B: a car dealership with 70 employees, $67 \%$ males, $55 \%$ with desk jobs; Company C: a sports complex, 20 employees, $80 \%$ males, $85 \%$ manual work; Company D: an animal fodder processing plant, 76 employees, $70 \%$ male industrial workers, Company $E$ : a steel fabrication plant, 80 male employees, heavy manual work.

Table 2: Episodes of sickness and days sick by employee category; rates per 1000 employees per annum.

\begin{tabular}{|c|c|c|c|c|c|c|c|}
\hline Episodes & $N$ & Total & Injury on duty & Sprains/strains & Low back pain & Psychological & URTI \\
\hline $\begin{array}{l}\text { Female manual } \\
\text { workers }\end{array}$ & 19 & $\mathrm{I}, 754$ & 0 & 351 & 53 & 18 & 526 \\
\hline $\begin{array}{l}\text { Male manual } \\
\text { workers }\end{array}$ & 207 & 3,277 & 153 & 692 & 135 & 35 & 879 \\
\hline $\begin{array}{l}\text { Female desk } \\
\text { workers }\end{array}$ & 78 & I,893 & 9 & 73 & 13 & 0 & 893 \\
\hline $\begin{array}{l}\text { Male desk } \\
\text { workers }\end{array}$ & 117 & 1,245 & 3 & 108 & 6 & 9 & 613 \\
\hline Days sick & $N$ & Total & Injury on duty & Sprains/strains & Low back pain & Psychological & URTI \\
\hline $\begin{array}{l}\text { Female manual } \\
\text { workers }\end{array}$ & 19 & 4,105 & 0 & 772 & 123 & 53 & 1,333 \\
\hline $\begin{array}{l}\text { Male manual } \\
\text { workers }\end{array}$ & 207 & 10,293 & 910 & $\mathrm{I}, 720$ & 565 & 230 & 2,283 \\
\hline $\begin{array}{l}\text { Female desk } \\
\text { workers }\end{array}$ & 78 & 4,231 & 21 & 145 & 38 & 0 & 2,171 \\
\hline $\begin{array}{l}\text { Male desk } \\
\text { workers }\end{array}$ & 117 & 3,570 & 291 & 248 & 14 & 145 & 1,558 \\
\hline
\end{tabular}

Legend: $\mathrm{N}=$ number of employees in each category Total = rate of sickness episodes per employee, for each category (total for all diagnoses) URTI

$=$ upper respiratory tract infection, including colds, sinusitis, flu, but excluding otitis media and chest infections

Maltese companies and employees, and no correction for employees' age and health status was possible. Furthermore no attempt at independent validation of doctors' diagnostic labelling or sick leave prescription was made.

The commonest diagnostic labels for sickness certification were found to be similar to those reported in the international literature $[2,3,6,7]$. However, the average duration of episodes of sickness absenteeism in Malta appears to be considerably less than what is reported in other European countries, even though the frequency of certification is similar (Table 4). Especially when compared to the Scandinavian countries and the $\mathrm{UK}$, the amount of work that has to be compensated because of sickness in Malta is considerably less $[10,11]$. It always has been one of the core responsibilities of family physicians to be aware of the economical, political and social conditions in which their patients live, and these also dictate the system in which 
Table 3: Odds ratio and relative risk of manual against desk workers having one or more episode of specified reasons for sickness certification in three years, with Chi-squared (Mantel Haenszel or Fisher's exact test) and $\boldsymbol{P}$-value.

\begin{tabular}{|c|c|c|c|c|c|c|}
\hline & & Injury on duty & Anxiety/depression & Sprains and strains & Low back pain & URTIs \\
\hline \multirow[t]{3}{*}{ Total } & Odds Ratio (95\% C.I.) & $19.03(6.81-73.18)$ & $6.68(1.52-60.8 I)$ & $7.46(4.63-12.03)$ & $7.89(3.23-23.10)$ & $0.79(0.47-1.35)$ \\
\hline & Chi-squared (Mantel Haenszel) & 53.18 & 8.18 & 83.04 & 27.92 & 0.82 \\
\hline & $P$ value & $<0.001$ & 0.004 & $<0.001$ & $<0.001$ & N.S. \\
\hline \multirow[t]{3}{*}{ Male } & Odds Ratio (95\% C.I.) & $25.47(6.46-218.18)$ & $3.97(0.88-36.57)$ & $6.54(3.74-11.48)$ & $9.84(3.01-50.58)$ & $0.91(0.48-1.73)$ \\
\hline & Chi-squared (Mantel Haenszel) & 38.46 & 3.78 & 53.38 & 19.89 & 0.09 \\
\hline & $P$ value & $<0.001$ & 0.05 & $<0.001$ & $<0.001$ & N.S. \\
\hline \multirow[t]{3}{*}{ Female } & Odds Ratio (95\% C.I.) & $0.00(0.00-22.55)$ & Undefined & $4.20(1.16-14.60)$ & $3.00(0.23-28.08)$ & $0.38(0.10-1.41)$ \\
\hline & Chi-squared (Mantel Haenszel) & Fisher's exact test & Fisher's exact test & Fisher's exact test & Fisher's exact test & Fisher's exact test \\
\hline & $P$ value & N.S. & N.S. & 0.021 & N.S. & N.S. \\
\hline
\end{tabular}

Legend: Total $=$ data for all employees calculated as one group Male/Female $=$ data for males/females calculated separately Injury on duty $=$ injury on duty (at workplace) Sprains and strains = muscular sprains and strains Low back pain = low back pain (excluding myalgia of the back, included in category above) Anixiety/depression = anxiety, depression, and other psychological diagnoses URTIs = upper respiratory tract infection, including colds, sinusitis, flu, but excluding otitis media and chest infections Odds ratio $=$ odds ratio of disease in manual against desk workers Chi-squared $=$ Chi-squared (Mantel Haenszel) or Fisher's exact test as calculated in Epi-Info, with appropriate P-value

Table 4: Certification in various European countries, described by researcher colleagues [12], reported in previous studies [2,7,13,14] or studied using Maltese doctors' electronic patient records [15]. Where data on sickness certification was not available, data on the total number of administrative procedures is used instead.

\begin{tabular}{|c|c|c|c|c|}
\hline Country & $\begin{array}{l}\text { Sickness certificates (when specified } \\
\text { - administrative procedures) }\end{array}$ & $\begin{array}{l}\text { Doctor's certificate needed } \\
\text { when? }\end{array}$ & $\begin{array}{l}\text { Re-certification needed after } \\
\text { what time? }\end{array}$ & $\begin{array}{l}\text { Coding of diagnostic title } \\
\text { on certificates? }\end{array}$ \\
\hline Austria & & $>3$ days & varies with diagnosis & not coded \\
\hline Flanders & $\begin{array}{l}5.4 \% \text { of interventions, } 17.9 \% \text { of } \\
\text { encounters [ } 13]\end{array}$ & day 1 & every month & not coded \\
\hline France & & day 1 & $\begin{array}{l}\text { FP may certify for long } \\
\text { periods }\end{array}$ & not coded \\
\hline Germany & & $>2$ days & one month & ICD-10 \\
\hline Hungary & & $\begin{array}{l}3 \text { days self-certification } \\
\text { once in a year }\end{array}$ & $\begin{array}{l}\text { I st week, then every two } \\
\text { weeks }\end{array}$ & ICD- 10 \\
\hline Israel & $\begin{array}{l}0.8 \% \text { of interventions were adminis- } \\
\text { trative procedures [13] II\% of con- } \\
\text { sultations [2] }\end{array}$ & $\begin{array}{l}\text { Ist day self-certified up to } \\
3-4 \text { times a year }\end{array}$ & $\begin{array}{l}\text { Varies, few days (FP) to } \\
\text { some months (specialist) }\end{array}$ & ICD-9 or (9-CM) \\
\hline Italy & $\begin{array}{l}3.6 \% \text { of reasons for encounter by } \\
\text { patients were sick certificate } \\
\text { requests [13] }\end{array}$ & day I & I week & not coded \\
\hline Malta & $\begin{array}{l}5.7 \% \text { of all reasons for encounter in } \\
\text { new episodes were for administra- } \\
\text { tive procedures; the latter requested } \\
\text { in } 8.2 \% \text { of all new episodes; } 4.7 \% \text { of } \\
\text { interventions; certificates issued in } \\
11.7 \% \text { of encounters and } 11.3 \% \text { of } \\
\text { episodes [ } 15]\end{array}$ & day 1 & one week & not coded \\
\hline Netherlands & $0.09 \%$ of encounters $[14]$ & self-certification & $\begin{array}{l}\text { social security physician, vari- } \\
\text { able time }\end{array}$ & $\begin{array}{l}\text { FPs not involved in certi- } \\
\text { fication process }\end{array}$ \\
\hline Norway & $12-17 \%$ of encounters [2] & $>3$ days & weeks & ICPC \\
\hline Poland & $2.0 \%$ of interventions [ 14$]$ & day 1 & up to six months & ICD-10 \\
\hline Portugal & & day 1 & every month & not coded \\
\hline Slovenia & & day I & every month & ICD- 10 \\
\hline Sweden & $8.8 \%$ of encounters [7] & day 8 & weeks & not coded \\
\hline United Kingdom & I8-35\% of consultations [2] & $>5$ days & $\begin{array}{l}\text { FP may certify for long } \\
\text { periods }\end{array}$ & not coded \\
\hline Wallonia & $\begin{array}{l}3.6 \% \text { of reasons for encounters were } \\
\text { for administrative procedures }[13]\end{array}$ & day 1 & every month & not coded \\
\hline
\end{tabular}


loss of income because of sickness is compensated. The explanation for this paradox may therefore be that it is a local phenomenon, but it is more likely that other studies may have ignored the important contribution of short-duration episodes of sickness. The observation that sickness certification episodes may be actually shorter on average than previously reported, when one takes into account sickness certification from day one, has important implications for further research in the field.

As expected, the frequency and total duration of episodes of injury on duty, low back pain and sprains and strains were higher in manual workers. However, the fact that the same appears true for anxiety and depression was not previously reported in the literature. This trend may become apparent as one considers short duration episodes of certification, as did the apparent paradox noted in the paragraph above. Possibly this trend may also be a local or even Mediterranean characteristic. However researchers and policy-makers alike should be made aware that manual workers may be more prone not only to excess physical but also psychological illness due to the strains and stresses of their work. Further research in this area is clearly needed, and the important contribution of short-duration episodes should be taken into account in all future studies. Since in many European countries certificates are not need from the first day of illness, this may pose difficulties in study design that may be difficult to overcome in such countries.

The striking number of work related problems (injuries on duty) and the significant differences in certification patterns between manual and non-manual workers, are indications of the relative lack of prosperity in Malta in comparison to many West-European countries. On the other hand, compared to data from other countries it is evident that Maltese workers relatively seldom receive sickness absenteeism compensation because of mood disorders, neurasthenia, long standing fatigue etc. It will be interesting to see how these patterns will change as Malta joins the European Union and changes its laws and regulations to comply with European standards.

\section{Conclusions}

The frequency of sick-leave certification in Malta is comparable to that in other European countries, but the average duration of certificates is much less than reported in other studies that generally did not include data on shortterm illness and certification. This has important implications of future research in the field. A number of common disorders were found to be significantly more prevalent causes of sickness certification in manual workers, amongst them anxiety and depression.

\section{List of abbreviations}

FP - Family Physician

URTI - Upper Respiratory Tract Infection

\section{Competing interests}

None declared.

\section{Glossary}

* Episode-oriented model: the database was structured so that subsequent periods of sickness in one individual, judged to be due to one illness event, were "joined" together to make one episode of sickness of a total duration of the sum of all days sick certified for that illness event, and given one diagnostic title.

\section{Acknowledgements}

The author also wishes to thank Prof. Dr. Henk Lamberts, Dr. Inge M. Okkes, Prof. Frank Dobbs, Prof. Christos Lionis, and Prof. Igor Svab for their invaluable assistance and suggestions that helped me in analysing the data and preparing this manuscript.

The author wishes to thank those who provided the data for analysis, namely Martin Cutajar, Aldo Fiorini, Alfred Grech, Anthony Mifsud, Kevin Navarro Gera, Mario R. Sammut, Ramon Scerri, and John Schembri. The other company FP was the author.

\section{References}

I. Agius Muscat $\mathrm{H}$ and Carabott $\mathrm{P}$ The content of general practice in Malta; a pilot study comparing Health Centre and Private practice in Malta with each other and with General Practice (as reported for other countries) Maltese Medical Journal 1989, I(2):34-45

2. Tellnes $G$ Sickness certification in general practice: a review Family Practice 1989, 6:58-65

3. Tellnes G, Svendsen K-O, Bjerkedal $T$ and Bruusgaard D Incidence of Sickness Certification Scand J Prim Health Care 1989, 7: I I -7

4. Hjortdahl $P$ and Borchgrevink $C$ Continuity of care: influence of general practitioners' knowledge about their patients on use of resources in consultations $B M J$ 1991, 303:1 I $81-4$

5. Murfin $D$ Medical sickness certification: why not review the role of the general practitioner? Editorial British Journal of General Practice 1990, 40:313-316

6. Himmel W, Sandholzer $\mathrm{H}$ and Kochen M Sickness certification in general practice European Journal of General Practice 1995, 1:161166

7. Englund $L$ and Svardsudd $K$ Sick-listing habits among general practitioners in a Swedish county Scand J Prim Health Care 2000, 18:8I-86

8. WHO World Health Report 2000. Health Systems: improving performance Geneva: World Health Organization 2000,

9. Malta Employers' Association Comparative analysis of sickness absence within the private and public sector, 1997-1999200I,

10. Tellnes G Days lost by sickness certification Scand J Prim Health Care 1989, 7:245-51

II. Tellnes $G$ Duration of episodes of sickness certification Scand J Prim Health Care 1989, 7:237-44

12. Data collected from WONCA (World Organisations of Family Doctors) and EGPRW (European General Practice Research Workshop) list-server subscribers via e-mail query in early 200I,

13. Lamberts H, Wood M, Hofmans-Okkes I and eds The International Classification of Primary Care in the European Community Oxford: Oxford University Press 1993,

14. Okkes IM, Polderman GO, Fryer GE, Yamada T, Bujak M, Oskam SK, Green LA and Lamberts $H$ The Role of family practice in different health care systems. A comparison of reasons for en- 
counter, diagnoses, and interventions in primary care populations in The Netherlands, Japan, Poland, and the United States J Fam Pract 2002, 5 I:72-73

15. Unpublished data from a study of electronic patient records from 10 private family practitioners in Malta, in collaboration with Okkes IM Data from 200I,

\section{Pre-publication history}

The pre-publication history for this paper can be accessed here:

http://www.biomedcentral.com/1471-2296/4/2/prepub

Publish with Bio Med Central and every scientist can read your work free of charge

"BioMed Central will be the most significant development for disseminating the results of biomedical research in our lifetime. "

Sir Paul Nurse, Cancer Research UK

Your research papers will be:

- available free of charge to the entire biomedical community

- peer reviewed and published immediately upon acceptance

- cited in PubMed and archived on PubMed Central

- yours - you keep the copyright

Submit your manuscript here:

http://www.biomedcentral.com/info/publishing_adv.asp 